\title{
Experience on temporary and permanent cardiac pacing after heart transplantation
}

\author{
Qiang $X u^{1,3}$, Lin-Hai $X \mathbf{u}^{2,3}$, Bai-Ming Qu ${ }^{1,3}$ and Qi $X \mathbf{u e}^{1,3}$ \\ ${ }^{1}$ Department of Cardiology, Zhejiang Provincial People's Hospital, Hangzhou 310014, China \\ ${ }^{2}$ Department of Cardiac Surgery, Zhejiang Provincial People's Hospital, Hangzhou 310014, China \\ ${ }^{3}$ People's Hospital of Hangzhou Medical College, Hangzhou 310014, China \\ Correspondence to: Qi Xue, email: xueq@zjheart.com \\ Bai-Ming Qu, email: qubm@zjheart.com \\ Keywords: cardiac pacing; heart transplantation; permanent cardiac pacing; temporary cardiac pacing \\ Received: August 07, $2017 \quad$ Accepted: December 28, $2017 \quad$ Published: January 02, 2018 \\ Copyright: $\mathrm{Xu}$ et al. This is an open-access article distributed under the terms of the Creative Commons Attribution License 3.0 \\ (CC BY 3.0), which permits unrestricted use, distribution, and reproduction in any medium, provided the original author and source \\ are credited.
}

\section{ABSTRACT}

Objectives: To evaluate and summarize the indications and outcome of cardiac pacing after heart transplantation.

Methods: We reviewed a total of 19 cases who received orthotopic heart transplantation with biatrial anastomosis at our hospital since 1997. Data of cases who received temporary or permanent cardiac pacing due to bradyarrhythmias during both perioperative and follow-up periods.

Results: Nine cases received temporary cardiac pacing after heart transplantation. In addition, seven of these cases received temporary cardiac pacing during the perioperative period most of them spontaneously recovered. Two cases received temporary cardiac pacing at late stage post-surgery after discontinuance of anti-rejection drugs, and died because of cardiac function deterioration during hospitalization. Four cases received permanent cardiac pacing, three at late stage postsurgery, another during perioperative period. All three cases received implantation of a dual-chamber pacemaker via conventional approach. After pacemaker implantation, patients were followed up for 6 months to 11 years, and parameters were all within the normal range. Two cases underwent device replacement because of battery exhaustion. Another patient developed infective endocarditis and secondary multiorgan failure after pacemaker implantation and didn't survive.

Conclusions: After orthotopic heart transplantation with biatrial anastomosis, the occurrence of bradyarrhythmia is higher during the perioperative period, which indicates the need for temporary cardiac pacing. A considerable number of cases will require cardiac pacing at the late stage post-implantation. Furthermore, bradycardia with severe heart failure may indicate signs of graft rejection.

\section{INTRODUCTION}

Heart implantation is a surgical transplant procedure that is performed on patients with end-stage heart failure when other medical or surgical treatments have failed. This approach can greatly improve the survival rate and quality of life of patients who suffer from heart failure [1]. However, a series of complications may occur after heart transplantation, and among them, bradycardia is the most common $[2,3]$. Although most patients spontaneously recover from bradycardia, a small number would need permanent cardiac pacing after implantation of the heart. However, only few studies have focused on the use of cardiac pacing after heart transplantation in China. In our hospital, some cases which dependent on cardiac pacing after heart transplantation were found since 1997. This study analyzed these cases to share experience about bradycardia after heart implantation. 


\section{METHODS}

\section{Clinical data}

From June 1997 to December 2016, a total of 19 cases underwent orthotopic heart transplantation with biatrial anastomosis for which conventional general anesthesia and extracorporeal circulation was used. Prior to surgery, all cases were confirmed as having end-stage dilated cardiomyopathy and heart failure. These cases were given anti-rejection treatment after surgery. A total of 7 cases were given $4 \mathrm{mg} / \mathrm{kg}$ ciclosporin or $15 \mathrm{ng} / \mathrm{kg}$ tacrolimus, $4 \mathrm{mg} / \mathrm{kg}$ azathioprine or $40 \mathrm{mg} / \mathrm{kg}$ mycophenolate mofetil, and glucocorticoids. The remaining 12 cases received quadruple immunosuppressive therapy, which included triple immunosuppressive therapy combined with the monoclonal antibodies daclizumab or basiliximab. Informed consent was obtained in all patients, and all transplant surgeries were approved by the Ethics Committee of Zhejiang Provincial People's Hospital. All the methods were carried out in accordance with the approved guidelines.

\section{Perioperative heart rate management and indications for temporary cardiac pacing}

All cases received placement of temporary epicardial pacing electrode in the right ventricle and were jointly monitored by the departments of cardiac and thoracic surgery, cardiology, and the intensive care unit. Parameters such as electrocardiography (ECG) were continuously monitored. Indications for postoperative temporary cardiac pacing were as follows: persistent sinus bradycardia $(<60$ beats $/ \mathrm{min})$, recurrent sinus pause, second- and third-degree atrioventricular block (AVB), poor control of frequent premature ventricular contractions, and bradycardia caused by necessary use of antiarrhythmic drugs. The epicardial pacing electrode was removed 2 weeks after heart implantation if temporary pacing is not necessary. The longest duration of temporary epicardial pacing was 1 month, and permanent pacemaker implantation was considered if the temporary epicardial pacing electrode could not be removed.

\section{Postoperative follow-up}

All cases received follow-up at the department of cardiac and thoracic surgery. Patients in need of cardiac pacing or other forms of cardiac treatment were transferred to the cardiology department.

\section{Perioperative caring and management of permanent pacemaker}

Indications for permanent pacemaker implantation were referred from the guidelines. The procedure for permanent pacemaker implantation was similar to that for ordinary patients who required a pacemaker. Antibiotics were given for a total of one week during the perioperative period. Sutures were removed a week after pacemaker placement. Patients had regular follow-up appointments at 1,3 , and 6 months after surgery, followed by a frequency of once every year. During follow-up, the status of the incision and parameters of the pacing electrode were examined.

\section{RESULTS}

\section{Temporary cardiac pacing}

After heart transplantation, a total of 9 out of 19 cases required and received temporary cardiac pacing $(9 / 19,47.4 \%)$. Seven patients received temporary cardiac pacing during the perioperative period, whereas two patients received temporary pacing at late stage postsurgery. The major reason for temporary cardiac pacing during the perioperative period was sinus node dysfunction (6/7, 85.7\%); 2 cases presented sinus bradycardia and in 4 cases sinus pause was detected. In all these cases, the above symptoms were observed shortly after surgery. Five cases had an intermittent onset of bradycardia, and hemodynamic changes were observed during the onset of bradycardia. In these cases, cardiac pacing combined with anti-rejection treatment gradually restored normal cardiac rhythm within one month after surgery, therefore the temporary pacemaker was removed. Another case presented persistent severe bradycardia after surgery and required cardiac pacing. A temporary pacemaker was placed after 5 weeks of surgery because of the failure of restoration of a normal cardiac rhythm. Due to the intermittent onset of three-degree AVB during the perioperative period $(1 / 7,14.3 \%)$, one case received temporary cardiac pacing. During this period, this patient underwent emergency rescue because of ventricular tachycardia (VT). However, the atrioventricular conduction was completely restored at 1 month after surgery. All cases who received temporary cardiac pacing during the perioperative period were finally discharged from the hospital. In addition, after discontinuance of anti-rejection drugs, two cases received temporary cardiac pacing at the late stage post-surgery. In these two cases, who presented with severe heart failure, the indications for cardiac pacing included third-degree AVB with syncope. A temporary pacing electrode was placed into the endocardium of the right ventricle via the central vein. The pacing threshold at which the cardiac pacing captured the myocardium was set at 10V. During hospitalization, two patients were died due to the deterioration of cardiac function in spite of antirejection treatment. For case description, see Table 1.

\section{Permanent cardiac pacing}

A total of four cases received permanent cardiac pacing $(4 / 19,21.1 \%)$. Because of persistent sinus bradycardia, one of these patients received permanent 
Table 1: Summary of cases receiving temporary cardiac pacing

\begin{tabular}{|c|c|c|}
\hline & Early stage after implantation & Late stage after implantation \\
\hline Case & 7 & 2 \\
\hline Sinus node dysfunction & 6 & 0 \\
\hline Reasons for implantation & & \\
\hline Third-degree AVB & 1 & 2 \\
\hline Clinical manifestation & $\begin{array}{l}\text { Bradycardia with chest tightness, and } \\
\text { hemodynamic changes in some cases }\end{array}$ & $\begin{array}{l}\text { Syncope caused by bradycardia, combined with } \\
\text { severe heart failure, hemodynamic disorders }\end{array}$ \\
\hline Outcome & $\begin{array}{l}\text { One case received a permanent } \\
\text { pacemaker due to persistent bradycardia. } \\
\text { In six cases, normal cardiac rhythm was } \\
\text { restored. All cases were discharged }\end{array}$ & Death \\
\hline Causes & $\begin{array}{l}\text { Intraoperative ischemia of donor heart, } \\
\text { probably leading to damage }\end{array}$ & $\begin{array}{l}\text { Discontinuance of anti-rejection drugs, } \\
\text { suspected of acute rejection }\end{array}$ \\
\hline
\end{tabular}

cardiac pacing during the perioperative period (1/4, 25\%). The remaining three cases received permanent cardiac pacing at late stage post-surgery $(3 / 4,75 \%)$. Two of these three cases presented sudden syncope due to third-degree AVB, whereas the third case presented with sinus pause. All cases underwent implantation of a dual-chamber pacemaker via a conventional approach. Ventricular pacing electrodes were successfully implanted in the right ventricular apex or septum. The pacing parameters obtained were satisfactory and lied within the normal range. Moreover, atrial pacing electrodes were implanted in the right atrial appendage. However, the atrial pacing electrode that was implanted in the right atrial appendage at a threshold of $10 \mathrm{~V}$ failed to capture the myocardium during surgery. Therefore, the position of the atrial pacing electrode was adjusted until reasonable pacing parameters were obtained. Preventive anti-infection treatment was given for one week post-surgery. After pacemaker implantation, cases were followed up for 6 months to 11 years. Electrode parameters such as pacing, sensing, and impedance were within the normal range. In two cases, the pacemaker battery was replaced due to battery exhaustion. After implantation of the pacemaker, one case presented with combined chronic kidney failure and required hemodialysis. However, during this period, the patient developed infective endocarditis. Although the infection could be controlled, this patient was later diagnosed with prostate cancer with secondary multi-organ failure and did not survive. The remaining three cases demonstrated class I-II cardiac function. Table 2 presents the summary of the conditions of the above-described cases.

\section{DISCUSSION}

In this study, we retrospectively analyzed the prevalence, indications, and outcome of cardiac pacing after heart transplantation, and summarized the experience of perioperative management of pacemakers. We found that a significant number of patients who received orthotopic heart transplantation with biatrial anastomosis suffered from sinus node dysfunction, for which temporary cardiac pacing was required. In addition, patients with an intermittent onset of bradycardia after surgery were found to recover spontaneously, whereas patients with persistent bradycardia who were dependent on pacing may ultimately require a permanent pacemaker due to complete loss of sinus node function. Moreover, severe bradycardia combined with heart failure may indicate graft rejection.

Heart transplantation is an effective treatment option for end-stage dilated cardiomyopathy. Although most patients enjoy an increased survival and show a higher quality of life after heart transplantation, complications such as rejection of the donor heart are still common [4]. Previous reports have shown that the prevalence of bradycardia, that needs to be treated by temporary pacing or other means of medication, is as high as 46\%-50\% [5-7]. In the majority of such cases, bradycardia is caused by sinus node dysfunction. However, in roughly $76 \%$ of patients normal cardiac rhythm will be restored within 3 weeks after surgery. Common causes of bradycardia include ischemia of the donor heart, surgical damage, and graft rejection. The current guidelines on indications for pacemaker placement after heart transplantation point out that a full assessment of the recovery of bradycardia should be performed before any decision on cardiac pacing is made [8]. In our study, $47.4 \%$ of cases had bradycardia that required application of temporary pacing after heart transplantation, which is in line with the incidence reported previously. Moreover, we found that paroxysmal bradycardia was likely to recover spontaneously, but that was not the case in patients who suffered from persistent bradycardia. Thus, different causes and severity of sinus node function may result in different clinical manifestations.

The number of patients who required permanent cardiac pacing is far higher among patients who underwent heart transplantation compared to ordinary patients. Different 
Table 2: Summary of cases receiving permanent cardiac pacing

\begin{tabular}{|c|c|c|c|c|c|c|c|}
\hline & Gender & $\begin{array}{l}\text { Time from heart } \\
\text { transplantation } \\
\text { to cardiac pacing }\end{array}$ & $\begin{array}{l}\text { Indications } \\
\text { for cardiac } \\
\text { pacing }\end{array}$ & $\begin{array}{l}\text { Type of } \\
\text { electrode } \\
\text { and device }\end{array}$ & $\begin{array}{l}\text { Duration } \\
\text { of follow- } \\
\text { up after } \\
\text { cardiac } \\
\text { pacing }\end{array}$ & $\begin{array}{l}\text { Status of } \\
\text { electrode and } \\
\text { device during the } \\
\text { follow-up }\end{array}$ & Other conditions during follow-up \\
\hline Case 1 & Male & 3 years & $\begin{array}{l}\text { Syncope } \\
\text { caused by } \\
\text { third-degree } \\
\text { AVB }\end{array}$ & $\begin{array}{l}\text { Passive } \\
\text { electrode, } \\
\text { DDD }\end{array}$ & 11 years & $\begin{array}{l}\text { Electrode } \\
\text { parameters in the } \\
\text { normal range, } \\
\text { replacement of } \\
\text { pacemaker } 8 \text { years } \\
\text { after implantation }\end{array}$ & $\begin{array}{l}\text { The case had class } 2 \text { cardiac function } \\
\text { after pacemaker implantation. He } \\
\text { had kidney failure } 2 \text { years after } \\
\text { replacement of pacemaker and received } \\
\text { hemodialysis. Atrial fibrillation and } \\
\text { infective endocarditis occurred. He was } \\
\text { diagnosed prostate cancer the next year } \\
\text { and died of multiple organ failure. }\end{array}$ \\
\hline Case 2 & Female & 5 weeks & $\begin{array}{l}\text { Symptomatic } \\
\text { sinus } \\
\text { bradycardia }\end{array}$ & $\begin{array}{l}\text { Passive } \\
\text { electrode, } \\
\text { DDD }\end{array}$ & 11 years & $\begin{array}{l}\text { Electrode } \\
\text { parameters in the } \\
\text { normal range, } \\
\text { replacement of } \\
\text { pacemaker } 9 \text { years } \\
\text { after implantation }\end{array}$ & Class 1 cardiac function \\
\hline Case 3 & Male & 9 years & $\begin{array}{l}\text { Syncope } \\
\text { caused by } \\
\text { third-degree } \\
\text { AVB }\end{array}$ & $\begin{array}{l}\text { Active } \\
\text { electrode, } \\
\text { DDD }\end{array}$ & 5 years & $\begin{array}{l}\text { Electrode } \\
\text { parameters in the } \\
\text { normal range, }\end{array}$ & $\begin{array}{l}\text { Class } 2 \text { cardiac function } \\
\text { Received autologous peripheral blood } \\
\text { stem cell transplantation for non- } \\
\text { Hodgkin lymphoma and was cured. }\end{array}$ \\
\hline Case 4 & Male & 13 years & $\begin{array}{l}\text { Syncope } \\
\text { caused by } \\
\text { sinus pause }\end{array}$ & $\begin{array}{l}\text { Active } \\
\text { electrode } \\
\text { DDDR }\end{array}$ & 6 months & $\begin{array}{l}\text { Electrode } \\
\text { parameters in the } \\
\text { normal range, }\end{array}$ & $\begin{array}{l}\text { Class } 2 \text { cardiac function } \\
\text { Paroxysmal atrial flutter }\end{array}$ \\
\hline
\end{tabular}

studies have indicated different figures, which vary from $8 \%$ to $24 \%[2,7]$. Daniel et al. used the organ transplantation database of the US and conducted statistical analysis in 35,987 cases who received heart transplantation between 1997 and 2007 [9]. In this study, it was found that permanent pacemaker implantation was performed in about $10.9 \%$ of cases. The surgical approach accounted as the primary risk factor for permanent pacemaker implantation. The risk for permanent pacemaker implantation among patients who received standard biatrial anastomosis increased 1.87-fold. The prevalence of cardiac pacing was significantly different at 30 days $(13 \%$ versus $0 \% ; P=0.008)$ and 90 days $(17 \%$ versus $1.8 \% ; P=0.01)$ in the cases using biatrial anastomosis and double vena cava anastomosis after heart transplantation [10]. This may be due because biatrial anastomosis preserves part of the posterior wall of the right and left atrium of the recipient and anastomosis is performed to the corresponding atria of the donor heart, which may cause damage to the sinus node. In contrast, double vena cava anastomosis preserves the intact right atrium of the donor heart, thereby avoiding surgical damage to the sinus node. In our study, a total of $21.1 \%$ of cases underwent cardiac pacing, which may be due to biatrial anastomosis. Regarding the timing of permanent pacemaker implantation, a previous study reported that $57.5 \%$ of cases underwent early implantation after surgery, whereas $42.5 \%$ of cases underwent late implantation [2]. Sinus node dysfunction is the key indication for early permanent pacemaker implantation, and atrioventricular nodal dysfunction is the key indicator for late permanent pacemaker implantation. To date, some consensus has been reached as to the indications for early cardiac pacing, in particular, sinus node injury. However, indications for late cardiac pacing have yet to be identified. Increasing evidence has shown that graft rejection as identified by conventional endomyocardial biopsy is not associated with cardiac pacing $[2,9]$. Another study reported a group of cases with graft rejection who showed bradycardia as the initial presentation at a late stage after heart transplantation [11]. Autopsy of cases who died from sudden syncope due to bradycardia revealed that graft rejection severely affected the cardiac conduction system, whereas the myocardium was only mildly affected. This indicated a close connection between bradycardia at late stage after heart transplantation and graft rejection. However, this is only rarely identified by the conventional endomyocardial biopsy approach. Of the 4 cases who received permanent cardiac pacing in our study, one case showed sinus node dysfunction as an indicator for early pacemaker implantation. Two cases, receiving late pacemaker implantation, had third-degree AVB, which was in line with previous studies. Another two cases showed bradycardia at late stage due to discontinuance of anti-rejection drugs. In both patients, bradycardia accompanied by severe heart failure, indicating simultaneous involvement of both the myocardium and the cardiac conduction system. These are convincing evidences that graft rejection is involved in bradycardia at late stage after heart transplantation.

Currently, the most common system in patients receiving orthotopic heart transplantation is a dualchamber pacemaker, with leads in the donor atrium and donor ventricle $\left(A_{D}-V_{D}\right)$. This pacing system could be 
managed to achieve a large variety of atrial and ventricular pacing settings in patients with or without AV blocks [12]. Donor hearts that are used during heart transplantation are denervated, and therefore physiological regulation of the donor heart is no longer affected by cardiac sympathetic nerves and vagus nerves of the recipient. This may lead to chronotropic incompetence, and therefore rateadaptive pacemakers are recommended. As mentioned above, biatrial anastomosis preserves part of the posterior walls of the right and left atrium of the recipient and anastomosis is performed to the corresponding atria of the donor heart. Therefore, the transplanted heart has two mutually isolated sinus nodes, each of which has independent electrical activities that can excite part of the atria to generate mutually independent P-waves. The residual atria of the recipient is enervated by the vegetative nervous system and displays a sufficient chronotropic response. By using the above electrophysiological features, Andrzej et al. experimented by inserting the atrial electrode into the residual right atrium to sense the original sinus rhythm of the recipient and the insertion of another electrode into the atrium of the transplanted heart for patients requiring permanent pacing due to sinus node dysfunction or chronotropic incompetence of the transplanted heart [13]. The data showed that the two atria were well synchronized, and the pacemaker rhythm was well regulated by autonomic nerves. The study show that atrial resynchronization could be achieved only in about $1 / 4$ patients with sinus node dysfunction after orthotopic heart transplantation, due to frequently noted electrophysiological changes in recipient atrium. And in transplanted heart patients, sensing and pacing conditions are more favorable in donor's than recipient's atrium. In our study, the atrial and ventricular electrodes were inserted in the donor heart of all patients. However, in one patient, cardiac pacing at a threshold of $10 \mathrm{~V}$ still failed to capture the myocardium. This patient had an atrial electrode inserted into the right atrial appendage of the donor heart. The atrial electrode was located at the suture line. The position of the atrial electrode in the right atrial appendage was repeatedly adjusted until reasonable pacing parameters were obtained. According to our study, the use of an active electrode allows for a more flexible positioning of electrode in the atrium.

Perioperative management and postoperative follow-up are of utmost importance for patients who receive permanent pacing after heart transplantation. These patients are usually immunocompromised due to the long-term use of anti-rejection drugs and therefore are very prone to infections. Aseptic manipulation should strictly be conducted during the perioperative period. To prevent infection, all patients were given antibiotics for one week perioperatively. Intravenous transfusion and invasive manipulation significantly increase the risk of infection. Infective endocarditis was observed in one case who received hemodialysis for kidney failure.
Only few domestic studies have been performed that focus on cardiac pacing after heart transplantation. Therefore, additional clinical studies will be required to increase our understanding on cardiac pacing after heart transplantation. We strongly believe that careful preoperative assessment and strict postoperative management are crucial for a successful outcome in patients who receive cardiac pacing after heart transplantation.

\section{CONFLICTS OF INTEREST}

The authors report no declarations of interest.

\section{FUNDING}

There was no financial support or funding for this article.

\section{REFERENCES}

1. Birati EY, Rame JE. Post-heart transplant complications. Crit Care Clin. 2014; 30:629-37. https://doi.org/10.1016/j. ccc.2014.03.005.

2. Cantillon DJ, Gorodeski EZ, Caccamo M, Smedira NG, Wilkoff BL, Starling RC, Saliba W. Long-term outcomes and clinical predictors for pacing after cardiac transplantation. J Heart Lung Transplant. 2009; 28:791-8. https://doi.org/10.1016/j.healun.2009.04.034.

3. DiBiase A, Tse TM, Schnittger I, Wexler L, Stinson EB, Valantine HA. Frequency and mechanism of bradycardia in cardiac transplant recipients and need for pacemakers. Am J Cardiol. 1991; 67:1385-9.

4. Feric NT, Radisic M. Strategies and Challenges to Myocardial Replacement Therapy. Stem Cells Transl Med. 2016; 5:410-6. https://doi.org/10.5966/sctm.2015-0288.

5. Miyamoto Y, Curtiss EI, Kormos RL, Armitage JM, Hardesty RL, Griffith BP. Bradyarrhythmia after heart transplantation. Incidence, time course, and outcome. Circulation. 1990; 82: IV313-7.

6. Redmond JM, Zehr KJ, Gillinov MA, Baughman KL, Augustine SM, Cameron DE, Stuart RS, Acker MA, Gardner TJ, Reitz BA, et al. Use of theophylline for treatment of prolonged sinus node dysfunction in human orthotopic heart transplantation. J Heart Lung Transplant. 1993; 12:133-8; discussion 8-9.

7. Woo GW, Schofield RS, Pauly DF, Hill JA, Conti JB, Kron J, Klodell CT, Singh R, Aranda JM Jr. Incidence, predictors, and outcomes of cardiac pacing after cardiac transplantation: an 11-year retrospective analysis. Transplantation. 2008; 85:1216-8. https://doi.org/10.1097/ TP.0b013e31816b677c.

8. European Society of C, European Heart Rhythm A, Brignole M, Auricchio A, Baron-Esquivias G, Bordachar P, Boriani G, Breithardt OA, Cleland J, Deharo JC, Delgado V, 
Elliott PM, Gorenek B, et al. 2013 ESC guidelines on cardiac pacing and cardiac resynchronization therapy: the task force on cardiac pacing and resynchronization therapy of the European Society of Cardiology (ESC). Developed in collaboration with the European Heart Rhythm Association (EHRA). Europace. 2013; 15:1070-118. https://doi. org/10.1093/europace/eut206.

9. Cantillon DJ, Tarakji KG, Hu T, Hsu A, Smedira NG, Starling RC, Wilkoff BL, Saliba WI. Long-term outcomes and clinical predictors for pacemaker-requiring bradyarrhythmias after cardiac transplantation: analysis of the UNOS/OPTN cardiac transplant database. Heart Rhythm. 2010; 7:1567-71. https://doi.org/10.1016/j. hrthm.2010.06.026.

10. Meyer SR, Modry DL, Bainey K, Koshal A, Mullen JC, Rebeyka IM, Ross DB, Bowker S, Wang S. Declining need for permanent pacemaker insertion with the bicaval technique of orthotopic heart transplantation. Can J Cardiol. 2005; 21:159-63.

11. Knight CS, Tallaj JA, Rayburn BK, Pamboukian SV, Bourge R, Kirklin JK, McGiffin D, Litovsky SH. Bradycardia and syncope as a presentation of cardiac allograft rejection involving the conducting system. Cardiovasc Pathol. 2010; 19:117-20. https://doi.org/10.1016/j.carpath.2008.10.006.

12. Thompson MA, Patel H. Posttransplant pacemaker placement: case series and review. Ochsner J. 2010; 10:236-40.

13. Kutarski A, Zakliczynski M, Oleszczak K, Kusnierz J, Lech B, Wojarski J, Kalarus Z, Przybylski R, WidomskaCzekajska T, Religa Z, Zembala M. Atrial resynchronization in patients after heart transplantation. Ann Transplant. 2002; 7:11-7. 